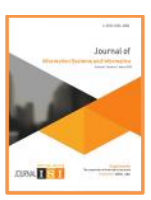

Vol. 3, No. 2, June 2021 e-ISSN: 2656-4882 p-ISSN: 2656-5935

\title{
Perencanaan Strategi Sistem Informasi Dengan Metode Ward And Peppard di Perusahaan Toko Surabaya cabang Surakarta
}

\author{
Adiatama Cahyo Setyo Waskito ${ }^{1}$, Augie David Manuputty ${ }^{2}$ \\ ${ }^{1}$ Fakultas Teknologi Informasi, Universitas Kristen Satya Wacana, Salatiga, Indonesia \\ ${ }^{2}$ Fakultas Teknologi Informasi, Universitas Kristen Satya Wacana, Salatiga, Indonesia \\ Email:1682017112@student.uksw.edu,2augie.manuputty@uksw.edu
}

\begin{abstract}
Abstrak
Peranan teknologi informasi begitu penting bagi kemajuan suatu perusahaan, dengan menggunakan teknologi informasi maka perencanaan strategis untuk perkembangan perusahaan akan semakin baik, beberapa perusahaan pasti akan memanfaatkan teknologi informasi untuk kemajuan perusahaanya, hal ini dimanfaatkam pula bagi Toko Baju Surabaya cabang Surakarta. Toko ini merupakan sebuah perusahaan yang bergerak di bidang penjualan pakaian, perusahaan ini menggunakan aplikasi SmartConsole untuk menunjang penjualan. Namun masih terdapat sektor-sektor di perusahaan ini yang masih belum menerapkan sistem informasi, salah satunya di bagian pendataan stok dan penggajian. Maka dari itu diperlukan perencanaan strategis SI/TI yang tepat. Penelitian ini dilakukan dengan menggunakan metode $W$ ard and Peppard dengan analisis SWOT, Five Forces Porter, dan McFarlan Strategic Grid. Output yang dihasilkan dari penelitian ini berupa rekomendasi strategi dari hasil analisa lingkungan internal dan eksternal sistem informasi perusahaan, serta usulan Sistem Informasi yang akan di petakan menggunakan McFarlan Strategic Grid untuk dapat diterapkan bagi perusahaan dalam dua tahun kedepan.
\end{abstract}

Kata Kunci: Perencanaan Strategis Sistem Informasi, $W$ ard and Peppard, SWOT, Five Forces Porter, McFarlan Strategic Grid

\section{PENDAHULUAN}

Perkembangan teknologi informasi pada beberapa dekade belakangan ini sangat pesat sehingga teknologi menjadi aset penting bagi kemajuan dan perkembangan suatu perusahaan maupun instansi manapun, bahkan penerapan SI/TI dalam dunia bisnis sangat dibutuhkan agar perusahaan atau organisasi dapat bersaing dengan kompetitornya[1]. Dengan mengoptimalkan pemanfaatan SI/TI pada suatu perusahaan atau organisasi akan menjadikan sebuah perusahaan atau organisasi menjadi lebih efektif dan efesien dalam pengambilan keputusan dan meningkatkan daya saing organisasi. Untuk memaksimalkan penerapan SI/TI yang sesuai dengan kapabilitas perusahaan atau instansi diperlukan perancangan strategi SI/TI yang sesuai dengan visi misi dari perusahaan tersebut[2]. 
Salah satu perusahaan yang sudah menerapkan pengelolaan SI/TI dalam setiap aktifitas bisnisnya adalah Toko Surabaya cabang Surakarta yang bergerak dalam bidang penjualan baju yang ada di kota Surakarta. Toko ini merupakan perusahaan cabang yang bergerak dibidang marketplace pada penjualan baju, celana, dress, baju anak, dan berbagai macam pakaian lainya. Meskipun Toko ini merupakan perusahaan cabang, namun toko ini memiliki omzet yang cukup besar, dikarenakan letak toko ini yang strategis serta berada di sektor pasar Klewer Surakarta, hal tersebut yang membuat toko ini selalu banyak pembeli. Toko ini memiliki SDM yang cukup banyak sekitar 30 orang yang dapat dipekerjakan secara shift. Selain itu sumber daya SI/TI di toko ini sudah berkembang begitu pesat sejak perusahaan ini didirikan pada tahun 2002, hal ini dibuktikan dengan adanya aplikasi SmartConsole yang sangat membantu menjalankan proses bisnis yang terdapat pada perusahaan. yang membantu perusahaan dalam penjualan, kemudian pengecekan stok barang, serta absensi pegawai dari fingerprint yang terintergrasi dengan aplikasi aplikasi SmartConsole. Selain itu aplikasi ini juga dapat menghitung pemasukan dan pengeluaran Toko, serta omset toko[3]. Namun dalam perkembangan teknologi sekarang ini, masih banyak sektor yang masih bisa dimanfaatkan dalam memaksimalkan kualitas SI/TI di Toko Surabaya cabang Surakarta ini agar lebih efesian dan efektif lagi kedepanya[4]. Oleh karena itu perlunya perencanaan strategi sistem informasi ini untuk perkembangan perusahaan agar lebih mampu bersaing dengan para kompetitornya serta mampu mempermudah jalanya proses bisnis yang berjalan di Toko Surabaya cabang Surakarta ini[5].

Dalam hal ini perencanaan strategi SI/TI di Toko Surabaya cabang Surakarta dapat menggunakan pendekatan melalui metode Ward and Peppard. Metode ini metode yang cocok untuk perkembangan aplikasi sistem informasi berbasis komputer yang mendukung perusahaan dalam penerapan proses bisnis perusahaan untuk mencapai tujuannya. Selain itu metode ini memiliki kerangka kerja yang efektif untuk menunjang kapabilitas perusahaan, diawali dengan analisis lingkungan bisnis internal serta eksternal, kemudian analisis strategi SI dan strategi TI[6]. Serta untuk menentukan strategi SI dan strategi TI yang dapat mendukung pencapaian visi dan misi perusahaan diperlukan pemahaman tentang strategi bisnis perusahaan. Teknik yang digunakan dalam metode analisis Ward and Peppard diperlukan analisis SWOT dan analisis Five Forces Porter, kemudian untuk hasil yang dicapai menggunakan McFarlan Strategic Grid untuk pemetaan portofolio aplikasi. Dengan begitu output yang dihasilkan dapat sesuai dengan harapan perusahaan untuk mencapai tujuan bisnis dari Toko Surabaya cabang Surakarta[7].

Dalam penelitian perencanaan Strategi SI/TI menggunakan Ward and Peppard yang dilakukan oleh Purnomo dan Febriliyan dengan judul "Perencanaan Strategis Sistem Informasi / Teknologi Informasi Di Balai Riset Dan Standarisasi Industri Surabaya" membahas tentang operasional bisnisnya dengan menggunakan pengelolaan TI yang dimilikinya, dengan tuntutan-tuntutan baru dari berbagai 
Vol. 3, No. 2, June 2021

p-ISSN: 2656-5935 http://journal-isi.org/index.php/isi e-ISSN: 2656-4882

pihak menyebabkan terganggunya pengelolaan TI, pengelolaan TI dirasa sudah tidak maksimal lagi untuk mendukung dan memaksimalkan strategi bisnis. Dalam penelitian tersebut pemecahan masalah yang digunakan adalah dengan menerapkan metode perencanaan strategi SI/TI dengan metode Ward and Peppard[8].

Penelitian lain yang dilakukan oleh Panca Anitasari yang berjudul "Perencanaan Strategi Sistem Informasi Dalam Meningkatkan Daya Saing Sekolah Pada SMK Komputer Mandiri Bajanbaru" membahas tentang manajemen, teknologi dan komunikasi di SMK Komputer Mandiri, dalam penelitianya, peneliti merasa perlu adanya perbaikan dalam hal kualitas SDM dalam memanfaatkan pengelolaan SI/TI dalam proses belajarnya, sehingga kualitas kelulusan dapat meningkat dalam menghadapi persaingan global. Solusi yang digunakan oleh peniliti dalam memecahkan masalah tersebut menggunakan perencanaan strategi SI/TI dengan metode Value Chain dan Five Force Porter[9]. Dari dua penelitian sebelumnya tersebut, dapat membantu penelitian perencanaan strategi sistem informasi pada Toko Surabaya cabang Surakarta dengan menggunakan metode Ward and Peppard dapat mendukung aktivitas bisnis perusahaan menjadi lebih maksimal dalam perkembangan dunia bisnis di era informasi ini.

\section{METODE}

Penelitian Toko Surabaya cabang Surakarta ini mengenai perencanaan strategi SI/TI dengan menggunakan metode pendekatan kualitatif, dimana dengan pendekatan ini dilakukan dengan cara melakukan riset untuk mengumpulkan data kemudian menganalisis data dari fakta yang terjadi pada objek studi kasus, sehingga menghasilkan instrumen kunci dari penelitian kemudian diuraikan dalam bentuk yang deskriptif[10].

Penelitian ini dilakukan dengan tahapan yang saling terhubung, dengan melakukan wawancara dengan pihak internal dari Toko Surabaya cabang Surakarta untuk mengumpulkan data terkait dengan penerapan penggunaan SI/TI di perusahaan, visi dan misi perusahaan, serta proses bisnis perusahaan. Data-data tersebut kemudian dianalisa dengan menggunakan metodologi Ward and peppard dengan beberapa teknis analisis, yaitu dengan analisis SWOT guna menemukan kekuatan, kelemahan, peluang dan ancaman dari lingkungan internal dan eksternal perusahaan, Five Force Porter untuk menganalisis persaingan bisnis dengan para kompetitor bisnis nya, kemudian McFarlan Strategic Grid yang dilakukan untuk pemetaan portofolio aplikasi yang mampu menunjang kinerja SI/TI dalam perkembangan bisnis perusahaan[11]. Pengambilan data ini bertujuan untuk menemukan masalah-masalah terkait kinerja bisnis perusahaan, agar peneliti mampu mendapatkan hasil berupa rekomendasi aplikasi untuk mengembangkan proses bisnis perusahaan[8]. 
Vol. 3, No. 2, June 2021

p-ISSN: 2656-5935 http://journal-isi.org/index.php/isi e-ISSN: 2656-4882

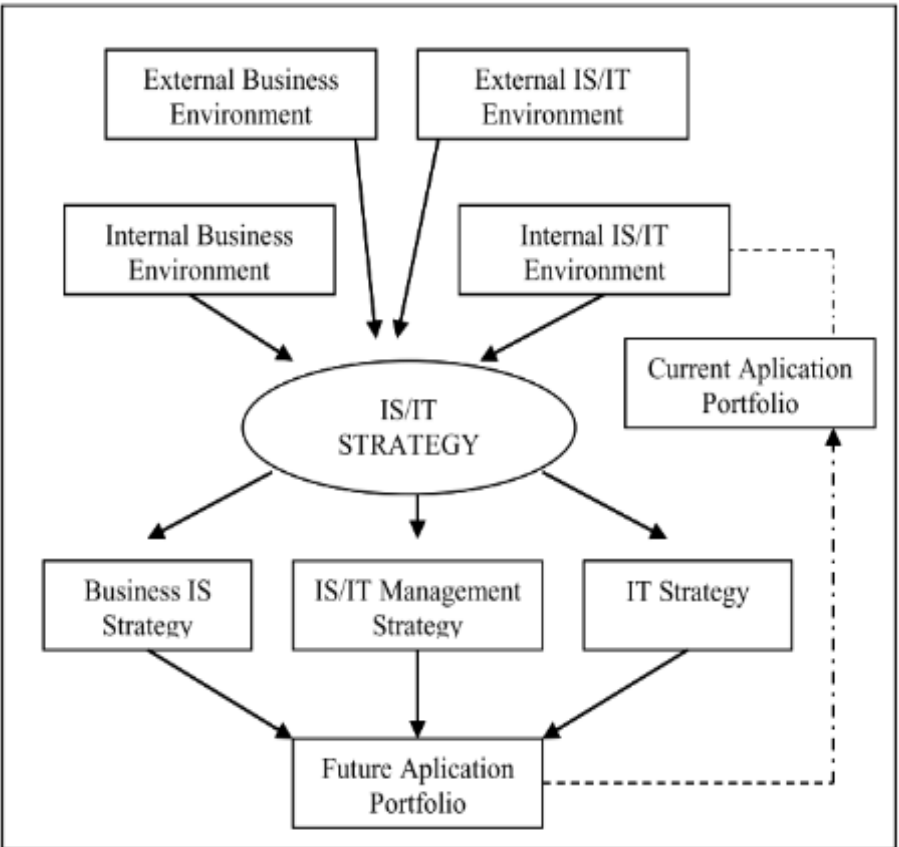

Gambar 1. Model Perencanaan Strategi SI/TI (Ward and Peppard 2002)

Tahapan masukan model perancangan strategi SI/TI

1. Analisis Lingkungan Bisnis Internal SI/TI

Pada tahap ini dilakukan analisis mengenai proses bisnis yang berjalan di Toko Surabaya cabang Surakarta untuk mendapatkan informasi mengenai hal-hal apa saja yang perlu dikembangkan

2. Analisis Lingkungan Bisnis Eksternal SI/TI

Tahap selanjutnya dilakukan analisis yang mencakup tentang persaingan dengan para kompetitor bisnis, agar mengetahui kekuatan bisnis dari para kompetitor, ancaman produk-produk sejenis, serta kekuatan dari pemasok dalam lingkungan eksternal bisnis dengan menggunakan metode Five Force Porter.

3. Analisis Lingkungan Internal SI/TI

Dalam tahap ini dilakukan analisis tentang kondisi SI/TI perusahaan, mengenai pemanfaatan sumber daya yang dimiliki perusahaan dalam menunjang SI/TI dalam pengaruhnya ke dalam bisnis perusahaan.

4. Analisis Lingkungan Eksternal SI/TI

Tahap berikutnya melakukan analisis yang mencakup pemanfaatan trend teknologi dari para costumer dan pesaing bisnis perusahaan.

Tahapan keluaran model perancangan strategi SI/TI

1. Strategi SI 
Vol. 3, No. 2, June 2021

p-ISSN: 2656-5935 http://journal-isi.org/index.php/isi

e-ISSN: 2656-4882

Mencakup rancangan strategi bisnis yang menggunakan pemanfaatan sistem informasi dalam mencapai target bisnis perusahaan.

2. Strategi TI

Mencakup rancangan strategi bisnis dengan memanfaatkan sumber daya IT yang terdapat di perusahaan.

3. Strategi Manajemen SI/TI

Mencakup strategi yang diterapan Toko Surabaya cabang Surakarta dalam mendapatkan penerapan SI/TI perusahaan.

Dari hasil analisis tersebut dapat dilakukan pemetaan dalam empat kuadran yaitu Strategic, High Potential, Key Operation, dan Support. Dari pemetaan yang sudah dilakukan, akan didapatkan gambaran aplikasi berbasis sistem informasi yang berguna untuk menunjang SI/TI perusahaan di masa mendatang. Hasil dari analisis cakupan SI/TI tersebut akan didapatkan sebuah pemetaan portofolio aplikasi dari metode McFarlan Strategic Grid[12].

\section{HASIL DAN PEMBAHASAN}

\subsection{Visi, Misi, Tujuan dan Sasaran Perusahaan}

\subsubsection{Visi Perusahaan}

Visi Toko Surabaya cabang Surakarta adalah menjadikan toko ini sebagai perusahaan pakaian yang profesional dengan kualitas produk yang mampu menjadi trendsetter di pulau jawa khusus nya cabang kota Surakarta.

\subsubsection{Misi Perusahaan}

Misi Toko Surabaya cabang Surakarta adalah sebagai berikut,

1. Memajukan produk pakaian yang berkualitas dengan desain yang ramah bagi masyarakat.

2. Menciptakan peluang pasar yang mempunyai potensi untuk berkembang.

3. Memacu kreativitas dan aktivitas dalam produksi serta penjualan.

4. Mendorong berkembangnya ekonomi kreatif dalam sektor usaha kecil dan menengah.

\subsubsection{Tujuan Perusahaan}

Menjadi perusahaan yang siap bersaing dengan kompetitor bisnis yang ada di kota Solo.

\subsubsection{Sasaran Perusahaan}

Sasaran penjualan tertuju untuk semua kalangan, baik anak muda, fashion pria dan wanita, orang tua sampai dengan anak-anak sekaligus.

Dari hasil wawancara serta observasi studi kasus langsung di Toko Surabaya cabang Surakarta, perusahaan ini masih belum mempunyai perencanaan strategis sistem informasi yang diterapkan di perusahaan ini. Oleh karena itu perlunya suatu perencanaan strategi sistem informasi untuk 
Vol. 3, No. 2, June 2021

p-ISSN: 2656-5935 http://journal-isi.org/index.php/isi

e-ISSN: 2656-4882

diterapkan di perusahaan agar membantu peningkatan kualitas perusahaan dan keunggulan kompetitif perusahaan. Penelitian ini dimulai dari melakukan analisis lingkungan internal dan eksternal perusahaan, lalu analisis SI/TI perusahaan, untuk kemudian menentukan strategi serta menentukan masukan dan usulan untuk perkembangan bisnis perusahaan.

\subsection{Analisis Lingkungan Bisnis Internal dan Eksternal 3.2.1. Analisis SWOT}

Analisis SWOT merupakan sebuah teknik yang digunakan untuk melakukan analisis kekuatan, kelemahan, peluang dan ancaman dari lingkungan internal dan eksternal perusahaan. Analisis SWOT dari Toko Surabaya cabang Surakarta adalah sebagai berikut.

\begin{tabular}{|c|c|c|}
\hline Eksternd & $\begin{array}{l}\text { (S) Strengtbs: } \\
\text { - } \quad \text { Harga lebih } \\
\text { terjangkau di } \\
\text { banding dengan } \\
\text { kompetitor lainya. } \\
\text { - Pelayanan } \\
\text { karyawan yang } \\
\text { mampu } \\
\text { memuaskan para } \\
\text { konsumen } \\
\text { Letaknya mudah } \\
\text { dicari karena } \\
\text { berada di samping } \\
\text { pasar klewer Solo. } \\
\text { - Memili } \\
\text { ki sistem bernama } \\
\text { SmartConsole yang } \\
\text { begitu membantu } \\
\text { jalanya proses } \\
\text { bisnis } \\
\end{array}$ & 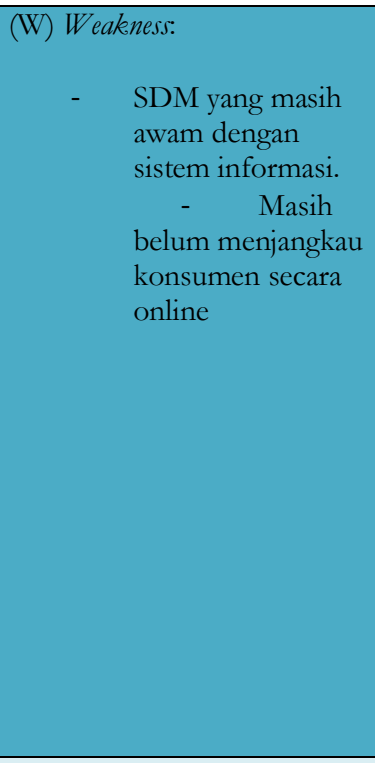 \\
\hline (O) Opportunities: & Strategi SO: & Strategi WO: \\
\hline $\begin{array}{l}\text { Meruapakan anak } \\
\text { perusahaan dari toko } \\
\text { pusat yang berada di } \\
\text { Surabaya. } \\
\text { - Stok } \\
\text { barang langsung dari } \\
\text { toko pusat dengan } \\
\text { harga yang relatif } \\
\text { lebih murah dari } \\
\text { distributor lainya }\end{array}$ & $\begin{array}{l}\quad 1 . \quad \text { Karena } \\
\text { perusahaan ini } \\
\text { merupakan anak } \\
\text { perusahaan dari } \\
\text { toko pusat, dan } \\
\text { stok barang } \\
\text { langsung dari } \\
\text { pusat maka } \\
\text { memiliki harga } \\
\text { yang lebih } \\
\text { terjangkau bagi } \\
\text { konsumen, maka } \\
\text { dari itu harus }\end{array}$ & $\begin{array}{l}\text { 1. Dengan jangkauan } \\
\text { pasar yang luas, } \\
\text { maka lebih baik } \\
\text { lagi jika bergerak di } \\
\text { bidang marektplace } \\
\text { online agar dapat } \\
\text { menjangkau lebih } \\
\text { banyak konsumen. } \\
2 . \quad \text { Dengan } \\
\text { SDM yang masih } \\
\text { awam maka lebih } \\
\text { baik jika } \\
\text { melakukan } \\
\end{array}$ \\
\hline
\end{tabular}


Vol. 3, No. 2, June 2021

p-ISSN: 2656-5935 http://journal-isi.org/index.php/isi e-ISSN: 2656-4882

\begin{tabular}{|c|c|c|}
\hline & $\begin{array}{l}\text { terus } \\
\text { mempertahankan } \\
\text { strategi ini. }\end{array}$ & $\begin{array}{l}\text { pelatihan SDM } \\
\text { agar lebih } \\
\text { memahami sistem } \\
\text { informasi } \\
\text { perusahaan. }\end{array}$ \\
\hline (T) Threats: & Strategi ST: & Strategi WT \\
\hline $\begin{array}{l}\text { - Karena berada di } \\
\text { sekitar pasar, banyak } \\
\text { perusahaan pesaing } \\
\text { yang bergerak } \\
\text { dibidang yang sama } \\
\text { Beberapa pesaing } \\
\text { sudah bergerak di } \\
\text { marketplace online } \\
\text { yang mampu } \\
\text { menjangkau } \\
\text { konsumen lebih luas } \\
\text { - Banyak } \\
\text { konsumen yang } \\
\text { lebih memilih } \\
\text { belanja online } \\
\text { daripada belanja } \\
\text { langsung ke toko. }\end{array}$ & $\begin{array}{l}\quad 1 . \quad \text { Memili } \\
\text { ki keinginan kuat } \\
\text { untuk } \\
\text { mengaplikasikan } \\
\text { marketplace secara } \\
\text { online agar } \\
\text { mampu } \\
\text { memperluas } \\
\text { jangkauan } \\
\text { konsumen, dan } \\
\text { tidak kalah dari } \\
\text { para kompetitor }\end{array}$ & $\begin{array}{l}1 . \quad \text { Melakuk } \\
\text { an pelatihan } \\
\text { kepada SDM } \\
\text { tentang penerapan } \\
\text { SI/TI yang akan } \\
\text { diimplementasikan } \\
\text { nantinya }\end{array}$ \\
\hline
\end{tabular}

Gambar 2. Matriks SWOT Toko Surabaya cabang Surakarta

Dalam analisis dari matriks SWOT yang tergambar pada Gambar 2. Dapat dilihat hasil dari analisis tersebut merujuk pada bergabungnya ke dalam marketplace online untuk mampu memperluas jangkauan konsumen. Gambaran ini untuk menyusun rencana perusahaan sehingga nantinya dapat memanfaatkan kekuatan internal dan peluang eksternal untuk meminimalisir kelemahan dan ancaman perusahaan sehingga dapat mencapai visi dan misi perusahaan

\subsubsection{Analisis Five Forces Porter}

Five Force Porter merupakan sebuah metode analisi yang akan digunakan untuk melakukan analisis serta identifikasi agar dapat menentukan pola bisnis dan identifikasi struktur industri perusahaan yang akan digunakan untuk mendapatkan hasil dari perencanaan strategis bisnis perusahaan. Hasil dari analisis Five Forces Porter dapat dilihat di gambar 3. 
Vol. 3, No. 2, June 2021

p-ISSN: 2656-5935 http://journal-isi.org/index.php/isi e-ISSN: 2656-4882

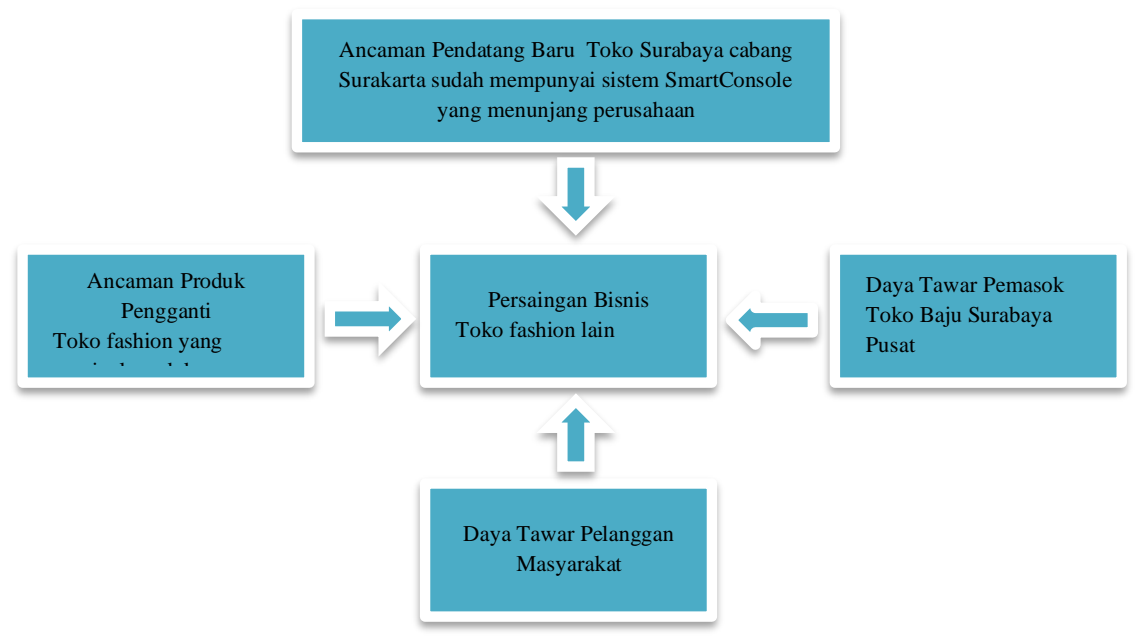

Gambar 3. Five Forces Porter Toko Surabaya cabang Surakarta

Pada analisis yang digambarkan pada Gambar 3. Metode ini menggunakan metode Five Force Porter, metode ini digunakan untuk menganalisa lingkungan eksternal dari perusahaan. Bagian pertama merupakan persaingan bisnis dengan perusahaan sejenisnya, Perusahaan memiliki strategi sendiri untuk mampu bersaing dengan perusahaan sejenis lain yakni pelanggan yang membeli produk di Toko baju Surabaya cabang Surakarta akan mendapatkan pelayanan yang terbaik.

Bagian kedua yaitu ancaman pendatang baru, toko di daerah pasar Klewer Solo banyak yang toko yang menjual produk sejenis dan beberapa dari mereka juga sudah memiliki SI/TI yang tidak kalah, dapat di kuatirkan dapat mengancam toko baju Surabaya ini, dalam hal ini Toko baju Surabaya dapat membangun atau membeli SI/TI yang dapat membantu kinerja proses bisnis perusahaan.

Bagian ketiga yaitu daya tawar pelanggan, Toko baju Surabaya cabang Surakarta memberikan harga produk yang ramah bagi masyarakat dan tidak terlalu tinggi dibanding toko lainya karena memang toko Surabaya cabang Surakarta ini mendapatkan produk langsung dari Toko Surabaya pusat sehingga harga yang didapat lebih murah.

Bagian keempat yaitu daya tawar pemasok, toko Surabaya cabang Surakarta memiliki pemasok langsung dari Toko Surabaya pusat yang berada di Surabaya yang memiliki banyak sekali pilihan produk.

Bagian kelima yaitu ancaman produk pengganti toko Surabaya cabang Surakarta dapat tergantikan oleh perusahaan lain, jika produk yang dijual perusahaan sejenis memiliki kualitas yang lebih baik dan harga yang lebih murah, oleh karena 
Vol. 3, No. 2, June 2021

p-ISSN: 2656-5935 http://journal-isi.org/index.php/isi e-ISSN: 2656-4882

itu Toko Surabaya cabang Surakarta harus terus menjaga kualitas produk dari waktu ke waktu, dan selalu mengutamakan kepuasan pelanggan.

\subsection{Analisa SI/TI Perusahaan}

Analisa SI/TI perusahaan menggunakan Mc Farlan Strategic Grid ini difungsikan guna melihat kondisi SI/TI perusahaan dengan daftar aplikasi yang dimiliki perusahaan adalah aplikasi SmartConsole dimana aplikasi ini sudah memiliki beberapa macam Sistem Informasi, mulai dari Sistem Informasi Kasir, Sistem Informasi Keuangan, dan Sistem Informasi Stok barang. Sedangkan untuk rekapitulasi bulanan menggunakan Microsoft Excel. Setelah dilakukan analisis, dan mengetahui sistem informasi yang ada di perusahaan, maka aplikasi SmartConsole dapat dipetakan menggunakan Mc Farlan Strategic Grid sebagai berikut.

Table 1. Sistem Informasi Toko Surabaya cabang Surakarta.

\begin{tabular}{|l|l|}
\hline \multicolumn{1}{|c|}{ STRATEGIC } & \multicolumn{1}{c|}{ HIGH POTENTIAL } \\
\hline 1. SI Kasir & \multicolumn{1}{c|}{ KEY OPERATIONAL } \\
\hline SUPPORT & $\begin{array}{l}\text { 1. SI Gudang } \\
\text { 2. SI Keuangan }\end{array}$ \\
\hline 1. Ms. Office (Exce) &
\end{tabular}

\subsection{Strategis TI}

Melihat kondisi dari perusahaan sendiri yang masih belum banyak menggunakan perangkat komputer maupun sejenis. Maka perlu dilakukan penambahan hardware dan juga memberikan ruangan khusus bagi hardware agar bisa dijaga dan dirawat dengan baik supaya tidak cepat rusak dan dapat bekerja dengan baik.

\subsection{Strategis Bisnis SI/TI}

Berdasarkan analisis dan observasi yang telah dilakukan di perusahaan tentang SI/TI, menghasilkan beberapa rekomendasi untuk perusahaan, sebagai berikut:

a. Membuat Aplikasi penjualan online, agar mampu menjangkau lebih banyak target pasar.

b. Menambah fitur yang terdapat di aplikasi SmartConsole dari Sistem Informasi Kasir dengan menambah scan barcode sehingga dapat lebih cepat dalam menentukan barang.

\subsection{Strategis Manajemen SI/TI}

Bagian IT sangat diperlukan untuk perusahaan guna menjalankan dan mengatur sistem informasi yang direncanakan dan dibuat di perusahaan. Bagian IT akan mengontrol, mengawasi permasalahan dari software maupun hardware sehingga dapat mengoptimalkan fungsi IT dengan baik. 
Vol. 3, No. 2, June 2021

p-ISSN: 2656-5935 http://journal-isi.org/index.php/isi e-ISSN: 2656-4882

\subsection{Usulan Aplikasi}

Berdasarkan hasil analisis yang diperoleh dari beberapa tahapan diatas yaitu analisis lingkungan bisnis perusahaan baik lingkungan internal maupun eksternal, sehingga akhirnya mendapatkan tahapan usulan strategi SI/TI untuk Toko Surabaya cabang Surakarta. Adapun usulan strategi sistem informasi untuk perusahaan ini adalah.

Table 2. Usulan Aplikasi Sistem Informasi di Toko Surabaya cabang Surakarta.

\begin{tabular}{|c|c|c|c|}
\hline No & $\begin{array}{c}\text { Nama Usulan Sistem } \\
\text { Informasi }\end{array}$ & Pengguna & Jenis Aplikasi \\
\hline 1 & $\begin{array}{l}\text { SI Penjualan } \\
\text { Pemberitahuan barang - } \\
\text { barang yang terjual, dan } \\
\text { beberapa transaksi yang } \\
\text { dihasilkan dalam } \\
\text { penjualan } \\
\text { tersebut. (Terintegrasi } \\
\text { dengan } \\
\text { SmartConsole) }\end{array}$ & Bagian Keuangan & Web atau mobile \\
\hline 2 & $\begin{array}{l}\text { Fitur SI Kasir } \\
\text { (Pemberitahuan kode } \\
\text { barang dari scan barcode } \\
\text { pada barang) }\end{array}$ & Karyawan & Desktop \\
\hline 3 & $\begin{array}{l}\text { SI Barang } \\
\text { (Pemberitahuan } \\
\text { rekapitulasi pada setiap } \\
\text { bulan) }\end{array}$ & Bagian gudang & Desktop \\
\hline 4 & $\begin{array}{l}\text { SI Penggajian ( } \\
\text { Pemberitahuan jumlah } \\
\text { gaji pegawai serta uang } \\
\text { bonus dan status apakah } \\
\text { sudah diterima atau } \\
\text { belum ) }\end{array}$ & Karyawan & Web atau mobile \\
\hline
\end{tabular}

Berdasarkan usulan sistem informasi yang ada maka akan dipetakan kedalam 4 kuadran Mc Farlan Strategic Grid untuk mengetahui prioritas aplikasi yang akan diterapkan oleh perusahaan untuk masa mendatang. Berikut adalah portofolio aplikasi secara keseluruhan Toko Surabaya cabang Surakarta masa mendatang. 
Vol. 3, No. 2, June 2021

p-ISSN: 2656-5935 http://journal-isi.org/index.php/isi e-ISSN: 2656-4882

Table 3. Pemetaan Sistem Informasi Toko Surabaya cabang Surakarta dengan $M c$ Farlan Strategic Grid

\begin{tabular}{|l|l|}
\hline \multicolumn{1}{|c|}{ STRATEGIC } & \multicolumn{1}{c|}{ HIGH POTENTIAL } \\
\hline 1. SI Kasir & 1. SI Penjualan \\
\hline \multicolumn{1}{|c|}{ SUPPORT } & \multicolumn{1}{|c|}{ KEY OPERATIONAL } \\
\hline $\begin{array}{l}\text { 1. SI Barang } \\
\text { 2. SI Penggajian }\end{array}$ & 1. SI Gudang \\
2. SI Keuangan
\end{tabular}

\subsection{Analisa Kesenjangan Aplikasi}

Analisa Kesenjangan Aplikasi digunakan untuk menentukan sistem informasi di Toko Surabaya cabang Surakarta untuk menentukan aplikasi apa saja yang memerlukan upgrade, delete, dan planning oleh Toko Surabaya cabang Surakarta. Berikut hasil Analisa kesenjangan aplikasi tersusun pada Table 4.

Table 4. Analisa Kesenjangan Aplikasi di Toko Surabaya cabang Surakarta.

\begin{tabular}{|l|c|c|c|}
\hline \multicolumn{1}{|c|}{ Aplikasi } & Upgrade & Delete & Planning \\
\hline SI Kasir & $\checkmark$ & - & - \\
\hline Ms. Office (Excel) & - & $\checkmark$ & - \\
\hline SI Penjualan & - & - & $\checkmark$ \\
\hline SI Penggajian & - & - & $\checkmark$ \\
\hline SI Barang & - & - & $\checkmark$ \\
\hline
\end{tabular}

\subsection{Pemetaan Implementasi Usulan Sistem Informasi}

Berdasarkan sistem informasi yang sudah diusulkan. Pemetaan implementasi akan membutuhkan waktu selama dua tahun kedepan guna mempertimbangkan keuangan dan waktu yang dimiliki perusahaan. Berikut adalah table menunjukan rencana implementasi usulan sistem informasi.

Table 5. Rencana Implementasi Sistem Informasi Toko Surabaya cabang Surakrta

\begin{tabular}{|l|c|c|}
\hline \multicolumn{1}{|c|}{ Solusi SI/TI } & $\mathbf{2 0 2 2}$ & $\mathbf{2 0 2 3}$ \\
\hline SI Penggajian & & Support \\
\hline SI Penjualan & & High Potential \\
\hline SI Barang & & Support \\
\hline
\end{tabular}


Vol. 3, No. 2, June 2021

p-ISSN: 2656-5935 http://journal-isi.org/index.php/isi e-ISSN: 2656-4882

\begin{tabular}{|l|c|l|}
\hline SI Kasir & Strategic & \\
\hline SI Gudang & Key Operational & \\
\hline SI Keuangan & Key Operational & \\
\hline
\end{tabular}

\section{KESIMPULAN}

Dari analisis serta observasi yang telah dilakukan, dapat disimpulkan bahwa analisis dengan menggunakan metode analisis SWOT dan Five Force Porter dapat mengetahui kondisi lingkungan internal dan eksternal perusahaan, hingga akhirnya metode McFarlan Strategic Grid dapat digunakan untuk perencanaan strategis SI/TI untuk perusahaan. Susunan strategi ini berupa rumusan dan rancangan aplikasi Sistem Informasi untuk kebutuhan perkembangan perusahaan Toko Surabaya cabang Surakarta. Sehingga dapat dilakukan pemetaan dari 4 kuadran sebagai hasil akhir penelitian, yaitu 1.) Kuadran Strategic: SI Kasir, 2.) Kuadran key operational: SI Keuangan dan SI Gudang, 3.) Kuadran Support: SI Penggajian dan SI Barang, 4.) Kuadran High Potential: SI Penjualan.

\section{DAFTAR PUSTAKA}

[1] A. D. Irfan Nur Arifani, "Perencanaan Strategis Sistem Informasi Dan Teknologi Informasi Pendidik Dan Tenaga Kependidikan," J. Teknol. Inf. Magister Darmajaya, vol. 02, no. 01, pp. 41-51, 2016.

[2] Anharudin, "Perencanaan Strategis Sistem Informasi Untuk Meningkatkan Pelayanan Menggunakan Metode Ward And Peppard ( Studi Kasus : Pt Pos Indonesia Cilegon - Banten)," J. PROSISKO, vol. 2, no. 2, pp. 1-4, 2015, [Online]. Available: http://ejurnal.lppmunsera.org/index.php/PROSISKO/article/view/103/161.

[3] J. Jesica and S. \& Kempa, "Analisis Strategi Bisnis Pada Click Fashion," Agora, vol. 4, no. 2, pp. 286-292, 2016.

[4] Ari Wedhasmara, "Langkah-Langkah Perencanaan Strategis Sistem Informasi Dengan Menggunakan Metode Ward And Peppard | Wedhasmara | Jurnal Sistem Informasi," Jsi, vol. VOL. 1, NO, no. 1, pp. 14-22, 2017, [Online]. Available: https://ejournal.unsri.ac.id/index.php/jsi/article/view/704.

[5] A. F. Wijaya and V. D. R. Damara, "Perencanaan Strategis Si/Ti Pada Document Management Menggunakan Ward and Peppard (Studi Kasus: Pt. Visionet Data International)," J. Bina Komput., vol. 2, no. 1, pp. 33-43, 2020, doi: 10.33557/binakomputer.v2i1.796.

[6] A. Wiyono and A. F. Wijaya, "Perencanaan Strategis Sistem Informasi Di Pt Telekomunikasi Indonesia, Tbk Witel Semarang Menggunakan Ward 
And Peppard," J. Bina Komput., vol. 2, no. 1, pp. 23-32, 2020, doi: 10.33557/binakomputer.v2i1.797.

[7] S. Kasus, C. V Grafika, P. Mitra, M. F. Johannis, A. R. Tanaamah, and P. Chernovita, "Metode Ward and Peppard," pp. 611-618.

[8] P. Y. Dewantara and F. Samopa, "Perencanaan Strategis Sistem Informasi / Teknologi Informasi Di Balai Riset dan Standardisasi (Baristand) Industri Surabaya," J. Teknol. Proses dan Inov. Ind., vol. 2, no. 2, 2017, doi: 10.36048/jtpii.v2i2.3211.

[9] P. Anitasari, "Perencanaan Strategi Sistem Informasi Dalam Meningkatkan Daya Saing Sekolah Pada SMK Komputer Mandiri Banjarbaru," J. Bianglala Inform., vol. 4, no. 1, pp. 68-75, 2016, [Online]. Available: https://ejournal.bsi.ac.id/ejurnal/index.php/Bianglala/article/view/661.

[10] F. Wibowo and A. F. Wijaya, "Perencanaan Strategis SI/TI Menggunakan Metode Ward and Peppard (Studi Kasus : Sinode GKJ)," Semin. Nas. Sist. Inf. Indones, no. November, pp. 39-44, 2018.

[11] N. S. Sasue and A. F. Wijaya, "Perencanaan Strategis Sistem Informasi Menggunakan Enterprise Architecture Planning (Eap) Framework," J. Bina Komput., vol. 2, no. 2, pp. 79-87, 2020, doi: 10.33557/binakomputer.v2i2.919.

[12] Y. Firmansyah, "Jurnal khatulistiwa informatika, vol. 3, no.1 juni 2015," $J$. Khatulistiwa Inform., vol. vol 3, no. no 1, pp. 105-118, 2015, [Online]. Available:

http://ejournal.bsi.ac.id/ejurnal/index.php/khatulistiwa/article/downloa $\mathrm{d} / 2304 / 1597$. 